\title{
EKSTRAKSI DAN KARAKTERISASI KARAGENAN KASAR RUMPUT LAUT Eucheuma cottoni
}

\section{[Extraction and Characterization of Crude Carrageenan from Seaweed Eucheuma cottoni]}

\author{
Asri Jaya ${ }^{{ }^{*}}$, Ni Ketut Sumarni ${ }^{1}$, Ahmad Ridhay ${ }^{1}$ \\ 1) Jurusan Kimia, Fakultas MIPA, Universitas Tadulako, Palu \\ J. Soekarno Hatta Km.9, Kampus Bumi Tadulako Tondo Palu, Telp. 0451- 422611 \\ *)Coresponding author: asrijayaarmb@gmail.com (087817054311) \\ Diterima 24 Desember 2018, Disetujui 23 Mei 2019
}

\begin{abstract}
Research on extraction and characterization of crude carrageenan from seaweed (eucheuma cottoni) has been carried out. The research aims to determine the optimum extraction time and temperature of crude carrageenan extract from seaweed (eucheuma cottoni). Crude Carrageenan was extracted from seaweed (eucheuma cottoni) by dissolving crushed seaweed in $8 \% \mathrm{KOH}$ with variation of extraction times are 1 hour, 1.5 hours, 2 hours, 2.5 hours and 3 hours, and temperatures are 50, 70, 90,110 and $130^{\circ} \mathrm{C}$. The results were analyzed using a Completely Randomized Design (CRD). The results show that the optimum extraction time in producing the best quality of crude carrageenan is 2 hours at $50^{\circ} \mathrm{C}$ with percentage is $78.4 \%$, viscosity is $9.155 \mathrm{cP}$, sulphate content is $3.102 \%$ and gel strength is $7 \mathrm{~g}$.
\end{abstract}

Keywords : eucheuma cottoni seaweed, crude carrageenan, characterization

\begin{abstract}
ABSTRAK
Telah dilakukan penelitian tentang ekstraksi dan karakterisasi karagenan kasar rumput laut jenis eucheuma cottoni. Penelitian ini bertujuan untuk mengetahui waktu dan suhu ekstraksi yang dapat menghasilkan karagenan kasar dengan rendemen dan mutu terbaik. Karagenan kasar dibuat dengan melarutkan rumput laut dalam $\mathrm{KOH} 8 \%$ dengan variasi perlakuan waktu pemasakan yaitu 1 jam, 1.5 jam, 2 jam, 2.5 jam dan 3 jam, dan suhu pemasakan yaitu 50, 70, 90, 110 dan $130^{\circ} \mathrm{C}$. Hasilnya dianalisis menggunakan Rancangan Acak Lengkap (RAL). Berdasarkan hasil yang diperoleh menunjukkan bahwa waktu pemasakan 2 jam dan suhu pemasakan $50^{\circ} \mathrm{C}$ menghasilkan karagenan kasar dengan rendemen dan mutu terbaik yaitu rendemen $78.4 \%$, viskositas $9.155 \mathrm{cP}$, kadar sulfat $3.102 \%$ dan kekuatan gel $7 \mathrm{~g}$.
\end{abstract}

Kata kunci : Rumput laut eucheuma cottoni, karagenan kasar, karakterisasi 


\section{LATAR BELAKANG}

Rumput laut merupakan salah satu jenis tanaman perairan yang saat ini banyak dibudidayakan oleh masyarakat Indonesia termasuk masyarakat Sulawesi Tengah. Rumput laut mempunyai prospek untuk dikembangkan terutama rumput laut jenis Eucheuma cottoni. Pada tahun 2009, Sulawesi Tengah termasuk penghasil rumput laut terbesar ketiga di Indonesia setelah Nusa Tenggara Barat (NTB) dan Sulawesi Selatan (Zatnika dan Istini, 2007 dalam Serdiati dan Widiastuti, 2010).

Rumput laut jenis Eucheuma cottoni selain memiliki daya tahan terhadap penyakit, juga mengandung karagenan kelompok kappa karagenan dengan kandungan yang relatif tinggi, yakni sekitar $50 \%$ atas dasar berat kering. Kappa karagenan bernilai ekonomi tinggi, yakni 10 sampai 20 kali harga rumput laut. Atas dasar tersebut kandungan karagenan rumput laut Eucheuma cottonii dijadikan sebagai faktor utama penentu mutu, dalam arti makin tinggi kandungan karagenan makin tinggi mutu rumput laut Eucheuma cottoni (Samsuari, 2006).

Karagenan adalah zat aditif alami yang banyak dimanfaatkan dalam berbagai industri, terutama industri makanan dan kosmetika. Karagenan kasar (SRC) adalah salah satu produk karagenan dengan tingkat kemurnian lebih rendah dibandingkan dengan karagenan murni. Karagenan kasar mengandung sejumlah kecil selulosa yang ikut mengendap bersama karagenan.
Karagenan kasar secara komersial diproduksi dari rumput laut jenis Eucheuma cottonii melalui proses pemanasan menggunakan larutan alkali Kalium Hidroksida (KOH) (Minghou, 2015).

Hasil penelitian Rizal et al. (2015), tentang optimalisasi produksi karagenan kasar dari rumput laut (Eucheuma cottoni) menghasilkan nilai konsentrasi $\mathrm{KOH}$ terbaik yakni $8 \%$ dari 3 konsentrasi $\mathrm{KOH}$ yang diujikan $(6 \%, 8 \%$ dan $10 \%)$ sedangkan waktu pemasakan terbaik yakni 60 menit dari 3 waktu pemasakan yang diujikan (30 menit, 45 menit dan 60 menit). Akan tetapi, waktu pemasakan masih dapat meningkatkan rendemen yang SRC dihasilkan.

Hudha et al. (2012), telah melakukan ekstraksi karagenan dari rumput laut dengan variasi suhu pelarut dan waktu operasi menghasilkan waktu dan suhu terbaik yaitu 2,5 jam dari empat waktu lainnya (0,5 jam, 1 jam, 1,5 jam, 2 jam, 2,5 jam dan suhu $90^{\circ} \mathrm{C}$ dari tiga suhu lainnya $\left(60^{\circ} \mathrm{C}, 70^{\circ} \mathrm{C}, 80^{\circ} \mathrm{C}\right)$ dengan rendemen sebesar $33,008 \%$.

Maka dari itu, dalam penelitian ini dilakukan penggunaan waktu pemasakan, dan suhu pemasakan yang menghasilkan karagenan kasar dari rumput laut Eucheuma cottoni yang menghasilkan rendemen dan mutu terbaik.

\section{METODE PENELITIAN}

\section{Bahan dan Peralatan}

Bahan yang digunakan dalam penelitian ini yaitu rumput laut Eucheuma 
cottonii, aquadest, $\mathrm{KOH}, \mathrm{HCl}, \mathrm{BaCl}_{2}$, aluminium foil, minyak, kain saring, lakban (Hitam dan bening) serta kertas saring whatman No.42.

Peralatan yang digunakan pada penelitian ini yaitu neraca analitik, blender, desikator, Vacuum, oven, hot plate, gegep, panci, kaca bening, saringan, viscometer Brookfield, TA-XT Plus Texture Analyzer, tanur, dan alat-alat gelas yang umum digunakan dalam Labotarium Kimia.

\section{Prosedur Penelitian}

\section{Persiapan Sampel}

Rumput laut Eucheuma cottoni dicuci dengan air mengalir dan direndam selama 24 jam. Selanjutnya, rumput laut dipotong-potong kecil dan dikeringkan dibawah sinar matahari hingga kering.

\section{Ekstraksi SRC (Rizal et al., 2015)}

Rumput laut kering sebanyak $25 \mathrm{~g}$ dimasukkan kedalam gelas kimia $250 \mathrm{~mL}$ dan ditambahkan $250 \mathrm{~mL}$ larutan $\mathrm{KOH} 8$ $\%$. Selanjutnya, dilakukan pemasakan pada suhu $50^{\circ} \mathrm{C}$ dengan variasi waktu masing-masing 1 jam, 1.5 jam, 2 jam, 2.5 jam dan 3 jam. Berdasarkan hasil karakteristik Kemudian dilanjutkan dengan variasi suhu pemasakan masing-masing $50^{\circ} \mathrm{C}, 70^{\circ} \mathrm{C}, 90^{\circ} \mathrm{C}, 110^{\circ} \mathrm{C}$ dan $130^{\circ} \mathrm{C}$ menggunakan waktu pemasakan terbaik. Setelah itu disaring dan dikeringkan dalam oven selama 4 jam pada suhu $60^{\circ} \mathrm{C}$. Ditimbang berat Karagenan kasar dan ditentukan rendemennya.

\section{Penentuan Rendemen}

Rendemen karagenan kasar dihitung berdasarkan massa karagenan kasar yang dihasilkan dibandingkan dengan massa rumput laut kering. Persamaan rendemen karagenan kasar ditentukan sebagai berikut:

Rendemen $=\frac{\text { Massa karagenan Kasar }(g)}{\text { Massa Rumput Laut Kering }(g)} \times 100 \%$

Analisis Kadar Sulfat (Distantina et al., 2010)

Analisis kadar sulfat dalam karagenan menggunakan metode hidrolisis dilanjutkan pengendapan sulfat sebagai barium sulfat. Sampel karagenan kasar ditimbang sebanyak 0,5 gram dan dimasukkan kedalam erlenmeyer yang ditambahkan $50 \mathrm{~mL}$ larutan $\mathrm{HCl} 0,1 \mathrm{~N}$. Sampel dipanaskan pada suhu didih selama 15 menit, dan ditambahkan $10 \mathrm{~mL}$ larutan $\mathrm{BaCl}_{2} \quad 0,25 \mathrm{M}$ diatas penangas air selama 5 menit. Larutan didinginkan selama 5 jam dan endapan yang terbentuk disaring dengan kertas saring. Endapan dicuci dengan akuades panas hingga bebas klorida. Sampel dibakar dalam furnace pada suhu $700^{\circ} \mathrm{C}$ selama 1 jam. Berat abu putih merupakan berat $\mathrm{BaSO}_{4}$. Perhitungan kadar sufat adalah sebagai berikut :

$$
\text { Kadar Sulfat }(\%)=\frac{(P X 0,4116)}{\text { Berat Sampel }} \times 100 \%
$$

Keterangan :

$$
\begin{aligned}
0,4116= & \text { Massa molekul } \mathrm{SO}_{4} \text { dibagi dengan } \\
& \text { massa molekul } \mathrm{BaSO}_{4}
\end{aligned}
$$

$\mathrm{P}=$ Berat endapan $\mathrm{BaSO}_{4}(\mathrm{~g})$ 


\section{Penentuan Viskositas}

Karagenan kasar dengan konsentrasi 8\% (b/v) disiapkan dengan aquades (2,5 gram karagenan kasar ditambah $250 \mathrm{~mL}$ aquades) kemudian dilarutkan dan diukur viskositasnya dengan menggunakan alat viscometer Brookfield. Pengukuran dilakukan pada suhu $30^{\circ} \mathrm{C}$ dengan laju geser $100 \mathrm{rpm}$. Pengujian ini menggunakan spindle no 2. Nilai viskositas dinyatakan dalam satuan Centipoise (cP).

\section{Penentuan Kekuatan Gel}

Pengukuran kekuatan gel dilakukan dengan menggunakan Texture Analyzer. Tepung rumput laut yang digunakan dalam bentuk karagenan kasar. Gel dipersiapkan dengan melarutkan $2 \mathrm{~g}$ bubuk karagenan kasar didalam $200 \mathrm{ml}$ aquades, larutan tersebut dipanaskan pada suhu $80^{\circ} \mathrm{C}$ sambil diaduk secara perlahan. Setelah semua karagenan terlarut dan tergelatimisasi, larutan kemudian dituangkan ke dalam pipa PVC $3 / 4$ inci dengan tinggi $3 \mathrm{~cm}$, lalu didinginkan dan dimasukkan didalam refrigerator pada suhu $10^{\circ} \mathrm{C}$ selama \pm 17 jam. Selanjutnya, kekuatan gel diukur dengan menggunakan alat TA-XT Plus Texture Analyzer dengan probe SMS P/35 dengan jarak $2 \mathrm{~cm}$.

\section{HASIL DAN PEMBAHASAN}

Pengaruh Waktu dan Suhu Ekstraksi Terhadap Rendemen Karagenan Kasar Rumput Laut Eucheuma cottoni

Rendemen karagenan merupakan persentase karagenan yang terdapat dalam sampel rumput laut yang dihasilkan menggunakan metode ekstraksi.

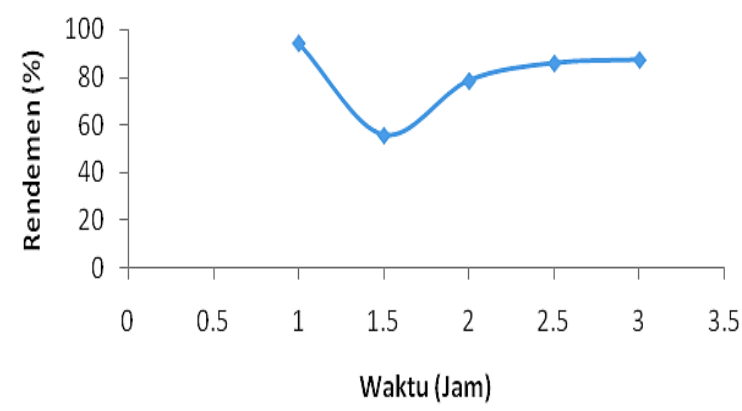

Gambar 1 Pengaruh waktu terhadap rendemen karagenan

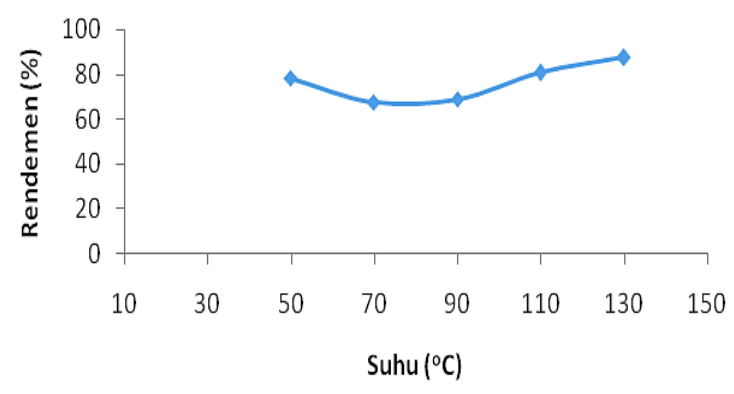

Gambar 2 Pengaruh suhu terhadap rendemen karagenan

Hasil menunjukkan nilai rendemen tertinggi sebesar $94,1 \%$ pada waktu ekstraksi 1 jam (Gambar 1). Tingginya nilai rendemen yang dihasilkan karena terlarutnya lapisan sel pada karagenan. Nurlaila et al. (2013) dalam penelitiannya tentang karakteristik biofilm berbahan dasar karagenan menunjukkan nilai rendemen tertinggi karagenan 45,64\% dengan waktu 1 jam dari dua waktu lainnya (2 jam dan 3 jam). Menurut

Hasil yang diperoleh menunjukkan nilai rendemen tertingi, yaitu $87,32 \%$ pada waktu 2 jam dan suhu $130^{\circ} \mathrm{C}$ (Gambar 2). Semakin tinggi suhu ekstraksi, maka semakin tinggi pula rendemen yang didapatkan. Ilham dan Arnold (2009) 
dalam penelitiannya tentang variabel proses pembuatan karagenan dari rumput laut dengan response surface methodology menunjukkan nilai rendemen tertinggi $46,35 \%$ pada suhu $85^{\circ} \mathrm{C}$ dibandingkan dengan suhu $65^{\circ} \mathrm{C}$. Menurut Ilham dan Arnold (2009) bahwa semakin tinggi suhu ekstraksi maka semakin tinggi nilai rendemen yang dihasilkan dikarenakan larutan pengekstrak semakin aktif sehingga semakin banyak karagenan yang terlepas dari dinding sel rumput laut.

Pengaruh Waktu dan Suhu Ekstraksi Terhadap Viskositas Karagenan Kasar Rumput Laut Eucheuma Cottoni

Viskositas merupakan kekentalan suatu cairan yang menunjukkan adanya ketebalan pada cairan yang bergerak. Menurut Giancoli (1998) zat cair viskositas disebabkan oleh gaya kohesif antar molekulnya, sedangkan pada gas viskositasnya berasal dari tumbukantumbukan antar molekulnya.

Hasil menunjukkan nilai viskositas tertinggi sebesar $9.335 \mathrm{cP}$ pada waktu ekstraksi 2.5 jam (Gambar 3). Semakin lama waktu ekstraksi maka semakin tinggi viskositas karagenan yang dihasilkan. Menurut Sumarni dan Sulastri (2017), meningkatnya viskositas larutan disebabkan meningkatnya waktu ekstraksi dan ukuran partikelnya semakin kecil. Namun, pada waktu 3 jam mengalami penurunan hal ini diakibatkan oleh penurunan gaya tolakan antar gugusgugus sulfat sehingga sifat hidrofilik polimer semakin lemah dan menyebabkan viskositas larutan menurun serta viskositas karagenan akan menurun drastis dengan naiknya suhu (Desiana dan Hendrawati, 2015).

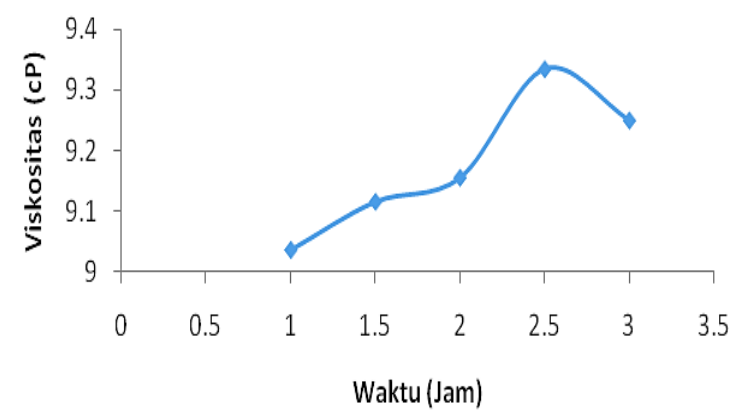

Gambar 3 Pengaruh waktu terhadap viskositas karagenan

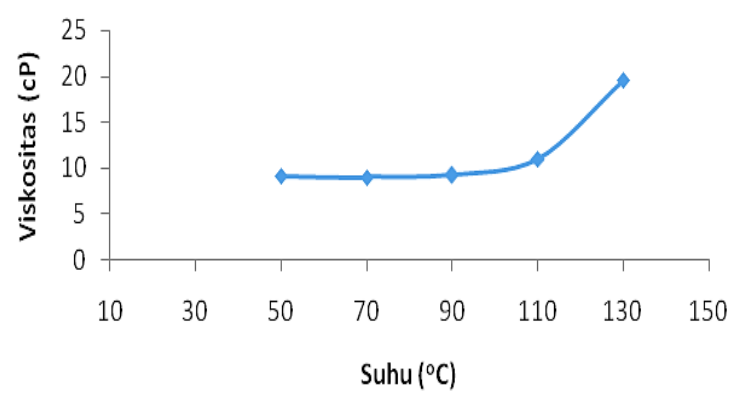

Gambar 4. Pengaruh suhu terhadap viskositas karagenan

Hasil menunjukkan nilai viskositas tertinggi sebesar 19,6 cP pada suhu ekstraksi $130^{\circ} \mathrm{C}$ (Gambar 4). Menurut Ningsih (2014), semakin kecil kandungan sulfat maka semakin kecil nilai viskositas yang dihasilkan. Hal ini dikarenakan garam-garam akan menurunkan viskositas karagenan dengan cara menurunkan tolakan elektrostatik diantara gugus sulfat.

Pengaruh Waktu dan Suhu Ekstraksi Terhadap Kadar Sulfat Karagenan Kasar Rumput Laut Eucheuma Cottoni

Kadar sulfat merupakan parameter untuk berbagai jenis polisakarida yang 
terdapat dalam rumput laut karaginan mempengaruhi sifat fisik seperti viskositas dan kekuatan gel (Winarno, 1996).

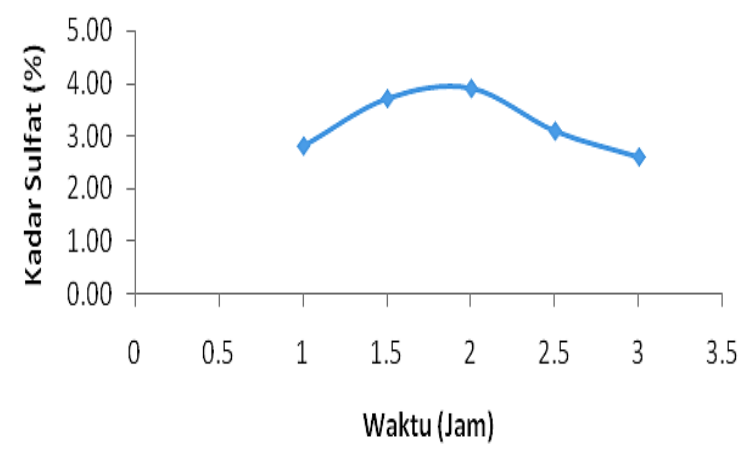

Gambar 5 Pengaruh waktu terhadap kadar sulfat karagenan

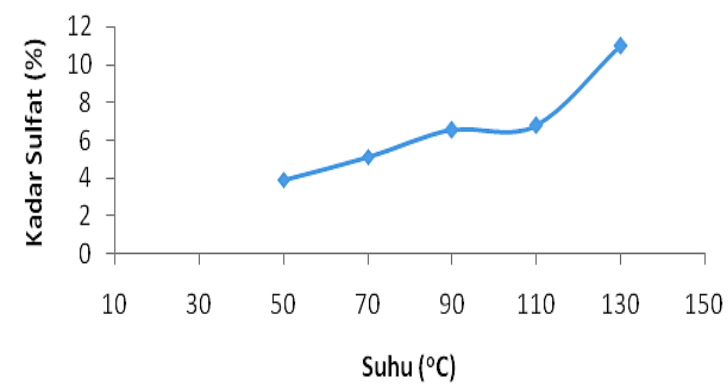

Gambar 6 Pengaruh suhu terhadap kadar sulfat karagenan

Hasil menunjukkan nilai kadar sulfat tertinggi sebesar 3,902\% pada waktu ekstraksi 2 jam (Gambar 5). Meningkatnya nilai kadar sulfat yang dihasilkan selaras dengan peningkatan nilai viskositas akibat pengaruh gugus sulfat yang mampu mengikat polimer karagenan. Menurut Campo et al. (2009), kandungan sulfat yang tinggi meningkatnya interaksi tolakan antar gugus sulfat yang bermuatan negatif sehingga rantai polimer karagenan semakin kuat dan elastis sehingga meningkatkan viskositas larutan.

Hasil menunjukkan nilai kadar sulfat tertinggi sebesar $10,963 \%$ pada suhu ekstraksi $130^{\circ} \mathrm{C}$ (Gambar 6). Semakin tinggi suhu maka semakin tinggi pula nilai kadar sulfat yang dihasilkan. Menurut Ningsih (2014), Semakin kecil kandungan sulfat maka nilai viskositasnya semakin kecil pula dikarenakan garam-garam akan menurunkan viskositas karagenan dengan cara menurunkan tolakan elektrostatik diantara gugus sulfat

\section{Pengaruh Waktu dan Suhu Ekstraksi Terhadap Kekuatan Gel Karagenan Kasar Rumput Laut Eucheuma cottoni}

Kekuatan gel merupakan sifat fisik yang utama, karena kekuatan gel menunjukkan kemampuan karaginan dalam pembentukan gel (Diharmi et al., 2011).

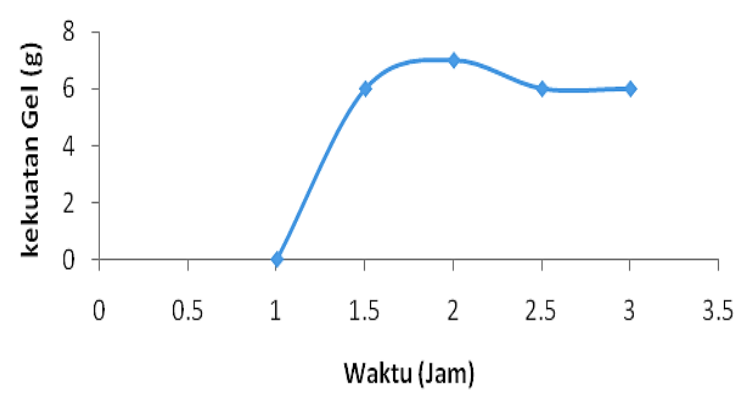

Gambar 7 Pengaruh waktu terhadap kekuatan gel karagenan

Hasil menunjukkan nilai kekuatan gel tertinggi sebesar 7 gram pada waktu ekstraksi 2 jam (Gambar 7). Semakin lama waktu ekstraksi semakin tinggi pula kekuatan gel yang dihasilkan. Menurut Sumarni dan Sulastri (2017), meningkatnya kekuatan gel disebabkan oleh gugus sulfat yang bermuatan negatif memiliki peluang berinteraksi dengan molekul air sehingga saat terjadi pembentukan gel sangat sulit dalam 
mempertahankan bentuk disaat mendapatkan tekanan dari luar sehingga menyebabkan kekuatan gel karagenan menurun.

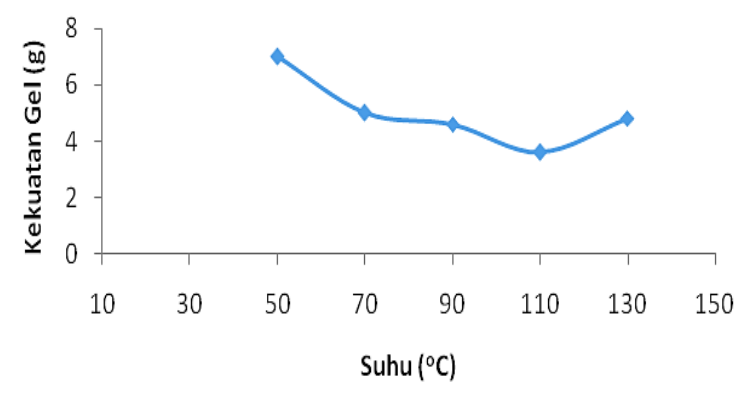

Gambar 8 Pengaruh suhu terhadap kekuatan gel karagenan

Hasil menunjukkan nilai kekuatan gel tertinggi sebesar 5 gram pada pada suhu $70^{\circ} \mathrm{C}$ (Gambar 8). Semakin tinggi suhu semakin rendah kekuatan gel yang dihasilkan dikarenakan Kadar sulfat yang tinggi. Menurut Wulandari (2010), tingginya kekuatan gel pada karagenan disebabkankan dengan sulfatnya lebih rendah dibandingkan karagenannya.
Spektrum FTIR Karagenan Kasar dari Rumput Laut Eucheuma cottoni

Spektrum FTIR pada karagenan yang dihasilkan menunjukkan adanya ikatan $\mathrm{S}=\mathrm{O}$ gugus ester sulfat pada spektrum 1240,23 $\mathrm{cm}^{-1}$, adanya ikatan CO gugus 3,6 anhidrogalaktosa pada spektrum 929,69 $\mathrm{cm}^{-1}$, dan adanya ikatan $\mathrm{C}-\mathrm{O}-\mathrm{SO}_{3}$ pada gugus galaktosa 4-sulfat yang menunjukkan kappa karagenan pada spektrum 860,25 cm-1 (Gambar 9). Hal ini menunjukkan spesifikasi gugus fungsi yang dihasilkan pada penelitian ini telah sesuai dengan produk kappa karagenan komersial. Menurut Fardhyanti dan Julianur (2015), menunjukkan adanya ikatan $\mathrm{S}=\mathrm{O}$ gugus ester sulfat pada spektrum 1227,67 $\mathrm{cm}^{-1}$, adanya ikatan CO gugus 3,6 anhidrogalaktosa pada spektrum 931,04 $\mathrm{cm}^{-1}$, dan adanya ikatan $\mathrm{C}-\mathrm{O}-\mathrm{SO}_{3}$ pada gugus galaktosa 4-sulfat yang menunjukkan kappa karagenan pada spektrum $848,19 \mathrm{~cm}^{-1}$.

Tabel 1. Perbandingan bilangan gelombang karagenan kasar dengan karagenan komersil dan hasil penelitian terdahulu

\begin{tabular}{cccc}
\hline \multicolumn{3}{c}{ Panjang Gelombang $\left.\mathbf{( c m}^{-1}\right)$} & \multirow{2}{*}{ Gugus Fungsi } \\
\cline { 1 - 3 } Karagenan kasar & Karagenan Komersial & $\begin{array}{c}\text { Fardhyanti \& } \\
\text { Julianur (2015) }\end{array}$ & \\
\hline 3414,00 & 3410,15 & - & $\mathrm{OH}$ \\
\hline 2927,94 & 2927,94 & - & $\mathrm{CH}$-alifatik \\
\hline 1639,49 & 1660,71 & - & $\mathrm{CH}$-alifatik \\
\hline 1240,23 & 1261,45 & 1227,67 & $\mathrm{~S}=\mathrm{O}$ \\
\hline 929,69 & 931,62 & 931,04 & $\mathrm{C}-\mathrm{O}$ \\
\hline 860,25 & 864,11 & 848,19 & $\mathrm{C}-\mathrm{O}-\mathrm{SO}_{3}$ \\
\hline
\end{tabular}




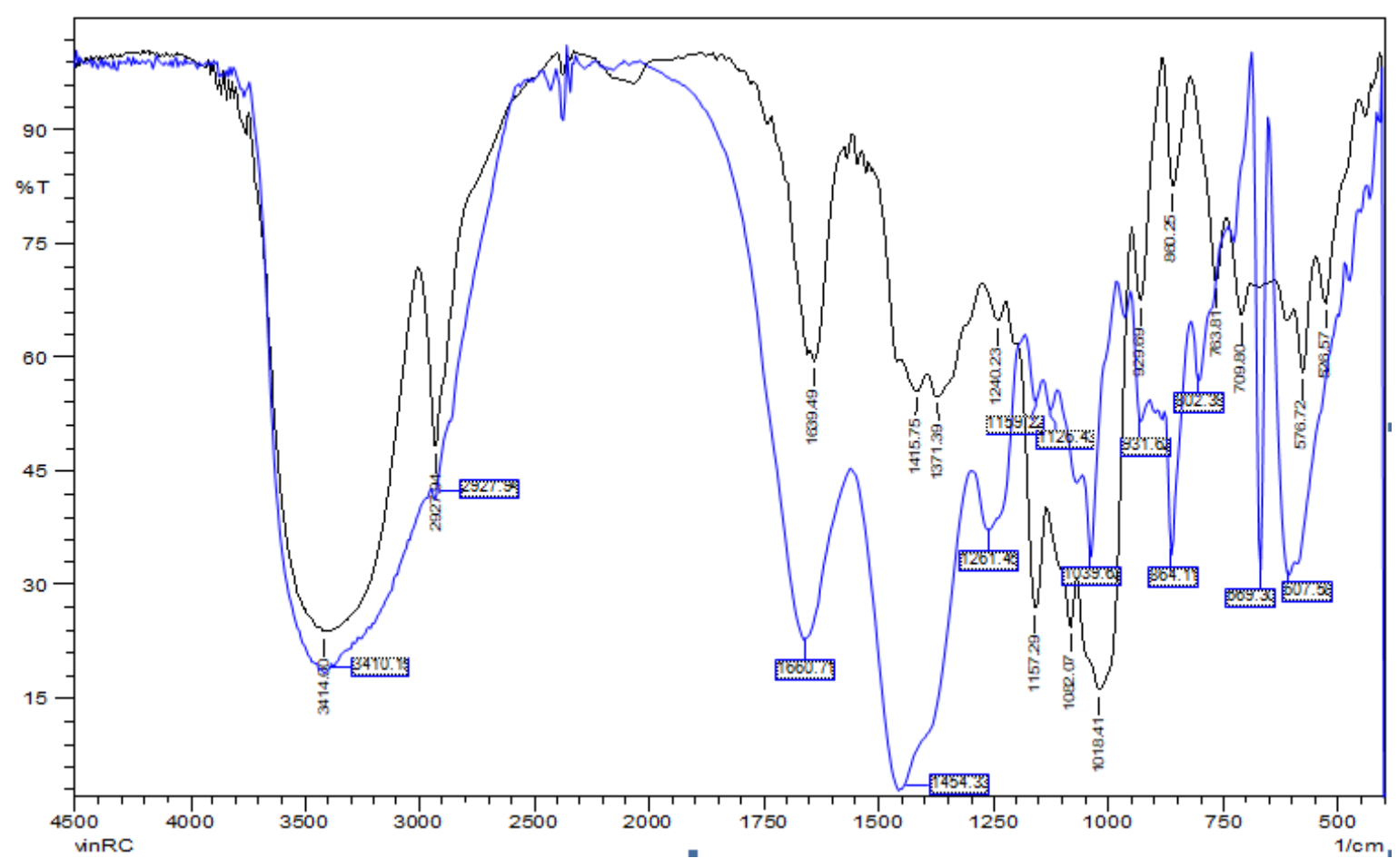

Keterangan :

---- : karagenan komersial

- : karagenan kasar

Gambar 9. Spektrum FTIR Karagenan Kasar

\section{KESIMPULAN}

Waktu dan suhu ekstraksi yang menghasilkan karagenan kasar dengan karakteristik terbaik terdapat pada perlakuan waktu 2 jam dan suhu $50^{\circ} \mathrm{C}$ dengan rendemen $78,4 \%$, viskositas 9,155 cP, kadar sulfat 3,902 \% dan kekuatan gel sebesar $7 \mathrm{~g}$.

Hasil FTIR karagenan kasar yakni ikatan $\mathrm{S}=\mathrm{O}$ gugus ester sulfat pada spektrum $1240.23 \mathrm{~cm}^{-1}$, adanya ikatan CO gugus 3,6 anhidrogalaktosa pada spektrum 929,69 $\mathrm{cm}^{-1}$, dan adanya ikatan $\mathrm{C}-\mathrm{O}-\mathrm{SO}_{3}$ pada gugus galaktosa 4-sulfat yang menunjukkan kappa karagenan pada spektrum $860,25 \mathrm{~cm}^{-1}$.

\section{DAFTAR PUSTAKA}

Campo, V.L., Kawano, D.F., Silva Júnior, D.B. and Ivone, C. I. 2009. Carrageenans: Biological Properties, Chemical Modifications and Structural Analysis. Carbohydrate Polymers, 77, 167-180.

Desiana, E. dan Hendrawati, T.Y. 2015. Pembuatan Karagenan Dari Eucheuma Cottoni Dengan Ekstraksi $\mathrm{KOH}$ Menggunakan Variabel Waktu Ekstraksi. Prosiding Semnastek 2015. Jakarta: FT UMJ 17 Movember 2015. Hal. 1-7.

Diharmi, A., Fardiaz, D., Andarwulan, N. dan Heruwati, E.S. 2011. Karakteristik karagenan hasil isolasi Eucheuma spinosum (alga merah) dari perairan Sumenep Madura. J. Perikanan dan Kelautan, 16(1):117124.

Distantina, S., Fadilah, Rochmadi, M. Fahrurrozi, dan Wiratni. (2010). Proses Ekstraksi Karagenan dari Eucheuma 
cottonii. Prosiding Seminar Rekayasa Kimia dan Proses. Hal : 21 : 1-6.

Fardhyanti dan Julianur. 2015. Karakterisasi Edible Film Berbahan Dasar Ekstrak Karagenan Dari Rumput Laut (Eucheuma Cottonii). Jurnal Bahan Alam Terbarukan 4(2): 68-73.

Giancoli, D. C. 1998. Fisika. Edisi ke-5 Terjemahan Yuhilza Hanum dan Irwan Arifin. Jakarta: Erlangga.

Hudha, M. H., Sepdwiyanti, R. dan Sari, S. D. 2012. Ekstraksi Karagenan Dari Rumput Laut (Eucheuma spinosum) Dengan Variasi Suhu Pelarut Dan Waktu Operasi. Berkala IImiah Teknik Kimia 1(1).

Ilham, dan Arnold, J.M. 2009. Optimasi Variabel Proses Pembuatan Karagenan Dari Rumput Laut (Eucheuma cottonii) Dengan Response Surface Methodology. Seminar Tugas Akhir S1 Teknik Kimia Universitas Diponegoro 2009. Semarang: FT UNDIP.

Minghou, J. 2015. Processing and Extraction Of phycocolloids. Institute of Oceanology, China: Academia Sinica Qingdao.

Ningsih, F. L. 2014. Jenis dan Konsentrasi Alkali dengan Presipitasi $\mathrm{KCl}$ yang Berbeda Terhadap Mutu Karagenan dari Rumput Laut Kappaphycus alvarezii Asal Pulo Panjang Serang Banten. Skripsi. Serang: Universitas Ageng Tirtayasa.

Nurlaila, E. H., Santoso, J., dan Salamah, E. 2013. Karakteristik Biofilm Berbahan Dasar Karagenan. Jurnal Akuatika IV(1): 10-20.

Rizal, M., Mappiratu, dan A. R. Razak. 2016. Optimalisasi Produksi Semi Refined Carrageenan (SRC) dari rumput laut (Eucheuma cottoni). KOVALEN 2(1):33-38.

Samsuari. 2006. Karakteristik Karagenan Rumput Laut Eucheuma Cottonii Pada Berbagai Umur Panen, Konsentrasi $\mathrm{KOH}$ dan Lama Ekstraksi. Tesis. Bogor: Sekolah
Pascasarjana Institut Pertanian Bogor.

Serdiati N, dan Widiastuti, I M. 2010). Pertumbuhan dan Produksi Rumput Laut Eucheuma cottonii pada Kedalaman Penanaman yang Berbeda. Media Litbang Sulteng. III (1): $21-26$.

Sumarni, N.K., dan Sulastri, E. 2017. Ekstraksi Dan Karakterisasi Dari Rumput Laut Jenis Eucheuma cottoni. Prosiding Seminar Nasional Kimia UNY 2017. Yogyakarta.

Winarno, F. G. 1996. Teknologi Pengolahan Rumput Laut. Jakarta: Pustaka Sinar Harapan. hlm 112.

Wulandari, R. 2010. Pembuatan Karagenan dari Rumput Laut Eucheuma cottonii dengan Dua Metode. Skripsi. Surakarta: Universitas Sebelas Maret. 